\title{
Molar root-incisor malformation: considerations of diverse (1) developmental and etiologic factors
}

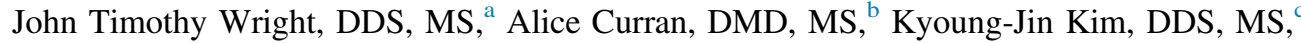 \\ Yeon-Mi Yang, DDS, PhD, ${ }^{\mathrm{d}}$ Soon-Hyeun Nam, DDS, PhD, ${ }^{\mathrm{e}}$ Teo Jeon Shin, MD, PhD, \\ Hong-Keun Hyun, DDS, PhD, ${ }^{c}$ Young-Jae Kim, DDS, PhD, ${ }^{c}$ Sang-Hoon Lee, DDS, PhD, ${ }^{c}$ \\ and Jung-Wook Kim, DDS, PhD ${ }^{\mathrm{c}, \mathrm{f}}$
}

Objective. The objective of this study was to evaluate the variation in the condition referred to as molar root-incisor malformation (MRIM) and elucidate the distribution of affected teeth. This study further aimed to identify associated environmental stressors.

Study Design. Individuals were identified through retrospective review of dental radiographs and through referral to the investigators. Histologic evaluation included examination of mineralized and decalcified sections of affected first permanent molar teeth.

Results. Thirty cases of MRIM were identified, with all having affected first permanent molars with dysplastic root formation. The primary second molars were affected in $57 \%$ of the cases, with permanent anterior teeth being involved in $40 \%$ of the cases. A variety of medical conditions were associated with MRIM, the most common being neurologic. Several affected individuals reported no significant past medical history or environmental stressors.

Conclusions. The etiology of MRIM remains unclear, and this unique developmental defect of the first permanent molar roots appears to occur in populations throughout the world. Clinicians identifying the MRIM phenotype should carefully evaluate the permanent incisors for associated developmental defects that could result in pulpal necrosis. (Oral Surg Oral Med Oral Pathol Oral Radiol 2016;121:164-172)

A novel dental phenotype has recently been described in several reports. This rather unique and specific phenotype shows variation in its severity but is characterized by diminished and dysplastic root formation of the first permanent molars and a narrow abnormal pulp chamber. These are the cardinal or primary features of this phenotype. The second primary molars are affected in some cases and appear similar to the first permanent molar defect, whereas the permanent anterior teeth can be involved and have constrictions of the crown in the cervical area and changes in the pulp chamber morphology. The first report of this condition described it as a root malformation associated with a cervical mineralized diaphragm, and a subsequent

This work was supported by grants by the National Research Foundation of Korea (NRF) grant funded by the Korea government (2014 R1A2A1A11049931).

${ }^{a}$ Department of Pediatric Dentistry School of Dentistry, University of North Carolina, NC, USA.

${ }^{\mathrm{b}}$ Department of Diagnostic Sciences, School of Dentistry, University of North Carolina, NC, USA.

${ }^{c}$ Department of Pediatric Dentistry \& Dental Research Institute, School of Dentistry, Seoul National University, Seoul, Korea.

${ }^{\mathrm{d} D}$ Department of Pediatric Dentistry, School of Dentistry, Chonbuk National University, Jeonju-si, Jeollabuk-do, Korea.

${ }^{\mathrm{e}}$ Department of Pediatric Dentistry, School of Dentistry, Kyungpook National University, Daegu, Korea.

${ }^{\mathrm{f}}$ Department of Molecular Genetics \& Dental Research Institute, School of Dentistry, Seoul National University, Seoul, Korea.

Received for publication May 31, 2015; returned for revision Aug 4, 2015; accepted for publication Aug 7, 2015.

(c) 2016 Elsevier Inc. All rights reserved.

2212-4403/\$ - see front matter

http://dx.doi.org/10.1016/j.0ooo.2015.08.024 report referred to is as "molar-incisor malformation." In this report, we present 30 new cases and refer to this new dental phenotype as molar root-incisor malformation (MRIM) to add clarity to the condition's name and help reduce possible confusion with other molarincisor defects, such as the highly prevalent condition called "molar-incisor hypomineralization."

Tooth development involves strict molecular control and regulation of developmental pathways that can be influenced by a variety of environmental factors. Through a series of epithelial-mesenchymal interactions, tooth formation begins with thickening of the oral epithelium and development of dental placodes. Tooth development can be divided into morphologically distinct steps, including the bud, cap, and bell stages. Specialized cells secrete unique extracellular matrices, which are processed to form the different mineralized tissues of dentin, enamel, and cementum.

\section{Statement of Clinical Relevance}

Molar root-incisor malformation appears to affect individuals with a past history of meningomyelocele, meningitis, or renal conditions more commonly but can occur in otherwise healthy individuals. Clinicians identifying affected individuals should carefully evaluate and monitor them for associated dental problems, including ectopic eruption, abscess, and tooth loss. 
Thousands of genes (the human dentome) are involved in the complex processes of tooth development, with many belonging to four major conserved pathways: TGF- $\beta$, Wnt, FGF, and Hedgehog. ${ }^{3,4}$ Genetic defects and environmental influences can cause failure of tooth development or abnormal morphologic changes of the tooth. ${ }^{5}$ There are hundreds of tooth abnormalities with a genetic etiology (nearly 100 affect enamel) and at least 100 known environmental causes of changes in tooth development. ${ }^{6,7}$

Compared with tooth enamel formation, the process of dentin development, or dentinogenesis, is thought to be relatively resistant to environmental insults or systemic conditions. It is the mesenchymally derived dentin that is the most abundant tissue in teeth and the tissue that determines much of the crown and root morphology. Hereditary dentin defects can be classified into dentinogenesis imperfecta (DGI) and dentin dysplasia (DD) ${ }^{8}$ These hereditary conditions are associated with abnormal dentin mineralization and varying degrees of changes in tooth morphology. DGI type I (Online Mendelian Inheritance in Man [OMIM] $\# 166200)$ is associated with osteogenesis imperfecta, whereas the clinically similar DGI type II (OMIM \#125490) is not associated with a syndrome and is caused by mutations in the gene encoding dentin sialophosphoprotein $(D S P P){ }^{9}$ The DGI tooth phenotype can have a pronounced cervical constriction at the cementoenamel junction area that demarcates the junction of the clinical crown and the tooth root. Individuals with DGI often have dental root structures that are diminished in size and appear sharp and "tent peg-like." DD type II, or the coronal DD type (OMIM \#125420) is an allelic disorder of DGI type II caused by DSPP mutations and is characterized by a similar phenotype in the primary dentition and slight or no discernable clinical phenotype in permanent dentition. ${ }^{10}$ The phenotype in DD type I, or radicular DD type (OMIM \#125400), is characterized by clinically normal-appearing tooth crowns and markedly altered dentin formation that has a pathognomonic cascading waterfall appearance histologically, pulp chamber obliteration, and abnormal to nearly missing root development. The etiology of this classic DD type I with normal crowns and unique histologic appearance is not known yet. ${ }^{10}$ Two affected individuals in the same family who had a phenotype of short roots and microdontia are listed in OMIM as having radicular dentin dysplasia. These cases were associated with a mutation in the SMOC2 gene found in the oral ectoderm and outer dental epithelium and in mesenchymal papillae facing the epithelial loops of molars and the only lingual loop of incisors. ${ }^{11}$ Depletion of the SMOC2 protein in zebrafish altered the expression of three major genes involved in
Table I. Summary of molar root-incisor malformation cases

\begin{tabular}{|c|c|c|c|}
\hline No. & Gender & Past medical history & Affected teeth \\
\hline 1 & M & Chronic renal failure & $3,14,19,30$ \\
\hline 2 & M & Chronic renal failure & $3,14,19,30$ \\
\hline 3 & $\mathrm{~F}$ & Meningomyelocele & $3,14,19,30$ \\
\hline 4 & M & $\begin{array}{l}\text { Sacral dimple, urinary } \\
\text { tract infection }\end{array}$ & $8,9,11,3,14,19,30$ \\
\hline 5 & M & Meningitis & $8,9,3,14,19,30$ \\
\hline 6 & $\mathrm{~F}$ & Meningomyelocele & $3,14,19,30$ \\
\hline 7 & M & Meningitis & $8,9,3,14,19,30$ \\
\hline 8 & M & Meningitis & $8,9,3,14,19,30$ \\
\hline 9 & $\mathrm{~F}$ & Meningitis & $\begin{array}{c}6,8,9,11,22,27,3, \\
14,19,30\end{array}$ \\
\hline 10 & M & $\begin{array}{l}2 \text { months preterm, } \\
\text { hydrocephalus }\end{array}$ & $8,9,3,14,19,30$ \\
\hline 11 & M & Stroke, hemiplegia & $\begin{array}{l}\mathrm{B}, \mathrm{A}, \mathrm{I}, \mathrm{J}, \mathrm{L}, \mathrm{K}, \mathrm{S}, \mathrm{T}, \\
\quad 3,14,19,30\end{array}$ \\
\hline 12 & M & Meningomyelocele & $\mathrm{K}, \mathrm{T}, 3,14,19,30$ \\
\hline 13 & $\mathrm{~F}$ & Meningitis & $\begin{array}{l}\mathrm{A}, \mathrm{J}, \mathrm{K}, \mathrm{T}, 6,8,3,14, \\
\quad 19,30\end{array}$ \\
\hline 14 & $\mathrm{~F}$ & Meningomyelocele & $\begin{array}{l}\text { A, J, K, T, 6, 8, 9, 11, } \\
\quad 3,14,19,30\end{array}$ \\
\hline 15 & M & $\begin{array}{l}\text { Speech disorder, } \\
\text { meningitis }\end{array}$ & $\begin{array}{l}\mathrm{A}, \mathrm{J}, \mathrm{K}, \mathrm{T}, 3,14,19, \\
\quad 30\end{array}$ \\
\hline 16 & $\mathrm{~F}$ & 2 months preterm & $\begin{array}{l}\text { A, J, K, T, 3, 14, 19, } \\
\quad 30\end{array}$ \\
\hline 17 & M & Cerebral thrombosis & $3,14,19,30$ \\
\hline 18 & $\mathrm{~F}$ & $\begin{array}{l}\text { Placenta previa, cerebral } \\
\text { palsy }\end{array}$ & $\begin{array}{l}\text { A, J, K, T, 3, 14, 19, } \\
\quad 30\end{array}$ \\
\hline 19 & $\mathrm{~F}$ & 1 month preterm & $3,14,19,30$ \\
\hline 20 & M & Meningomyelocele & $\begin{array}{l}\text { A, J, K, T, 3, 14, 19, } \\
\quad 30\end{array}$ \\
\hline 21 & $\mathrm{~F}$ & Healthy & $\begin{array}{l}\text { A, J, K, T, 3, 14, 19, } \\
\quad 30\end{array}$ \\
\hline 22 & $\mathrm{~F}$ & Sacral dimple & $\begin{array}{l}\text { A, J, K, T, 3, 14, 19, } \\
\quad 30\end{array}$ \\
\hline 23 & M & Healthy & $8,9,3,14,19,30$ \\
\hline 24 & $\mathrm{~F}$ & Meconium aspiration & $8,9,3,14,19,30$ \\
\hline 25 & $\mathrm{~F}$ & Healthy & $3,14,19,30$ \\
\hline 26 & M & $\begin{array}{l}\text { Severe Escherichia coli } \\
\text { Infection, renal } \\
\text { malfunction/ } \\
\text { hemolytic anemia }\end{array}$ & $\begin{array}{c}\text { A, J, K, T, 5, 6, 7, 8, } \\
9,10,11,22,23, \\
24,25,26,27,28, \\
3,14,19,30\end{array}$ \\
\hline 27 & M & $\begin{array}{l}\text { Jaundiced birth, } \\
\text { questionable } \\
\text { cerebrovascular } \\
\text { accident, short stature }\end{array}$ & $\begin{array}{l}\text { A, J, K, T, 3, 14, 19, } \\
\quad 30\end{array}$ \\
\hline 28 & M & $\begin{array}{l}\text { Numerous childhood } \\
\text { illnesses and } \\
\text { treatments with } \\
\text { antibiotics }\end{array}$ & $\begin{array}{l}\text { A, J, K, T, 8, 9, 3, 14, } \\
\quad 19,30\end{array}$ \\
\hline 29 & M & Healthy & $\begin{array}{l}\text { A, J, K, T, 3, 14, 19, } \\
\quad 30\end{array}$ \\
\hline 30 & $\mathrm{M}$ & 2 months preterm & $\begin{array}{l}\text { A, J, K, T, 3, 14, 19, } \\
30\end{array}$ \\
\hline
\end{tabular}

odontogenesis: Dlx2, bmp2, and pitx $2 .{ }^{11}$ These human and zebrafish studies confirmed the important role of the SMOC2 gene in tooth formation. It seems likely that the classic phenotype of radicular DD described by Witkop et al. is caused by a different gene. ${ }^{8,12}$ 


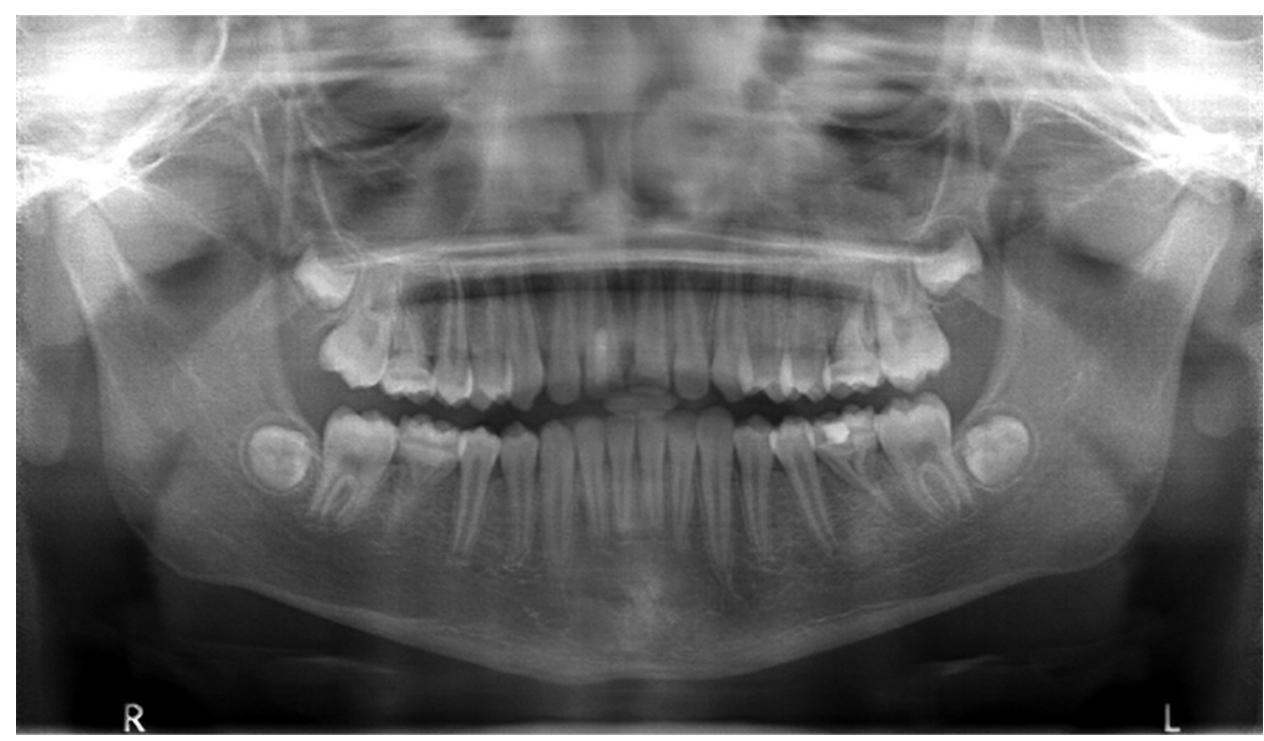

Fig. 1. All four first permanent molars and the maxillary central incisors are affected in this individual. Teeth \#8 and \#20 both have periapical pathology. Note the normal appearance of the second permanent molars (case 24).
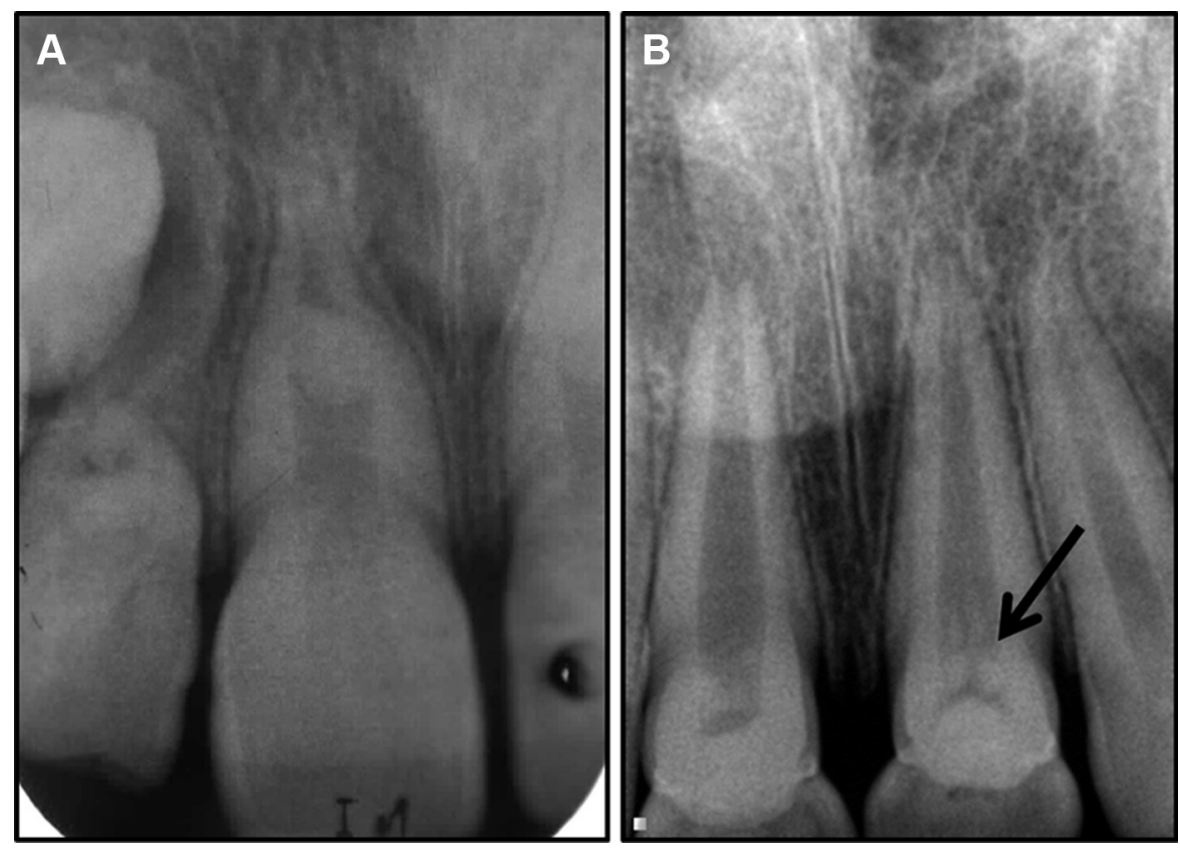

Fig. 2. The permanent central incisors exhibit a marked shortening of the root with a large pulpal obstruction in the middle root area (A) (radiograph of case 26). The permanent central incisors show a dramatic constriction in the cervical area (B) of the clinical crown and a dens-in-dente type appearance in the pulp (arrow). Tooth \#8 has an apical abscess in the absence of any dental caries (case 24).

Other known genetic causes of abnormal root formation include truncated root formation caused by mutations in the IFIHI gene and Singleton-Merten syndrome 1 (OMIM \#182250). ${ }^{13}$ Individuals with tumoral calcinosis (TC, OMIM \#211900) can have short bulbous roots. ${ }^{14}$ TC is caused by mutations in the GALNT3 gene, which codes for an enzyme that initiates O-glycosylation of serine and threonine residues and can activate FGF23, which is a phosphaturic protein and can cause TC as well. ${ }^{15}$ Short dental roots are also seen with sponastrime dysplasia (OMIM \#271510) and Bardet-Biedl syndrome 1 (OMIM \#209900). ${ }^{16,17}$ The hereditary condition known as Kenny-Caffey syndrome (OMIM 

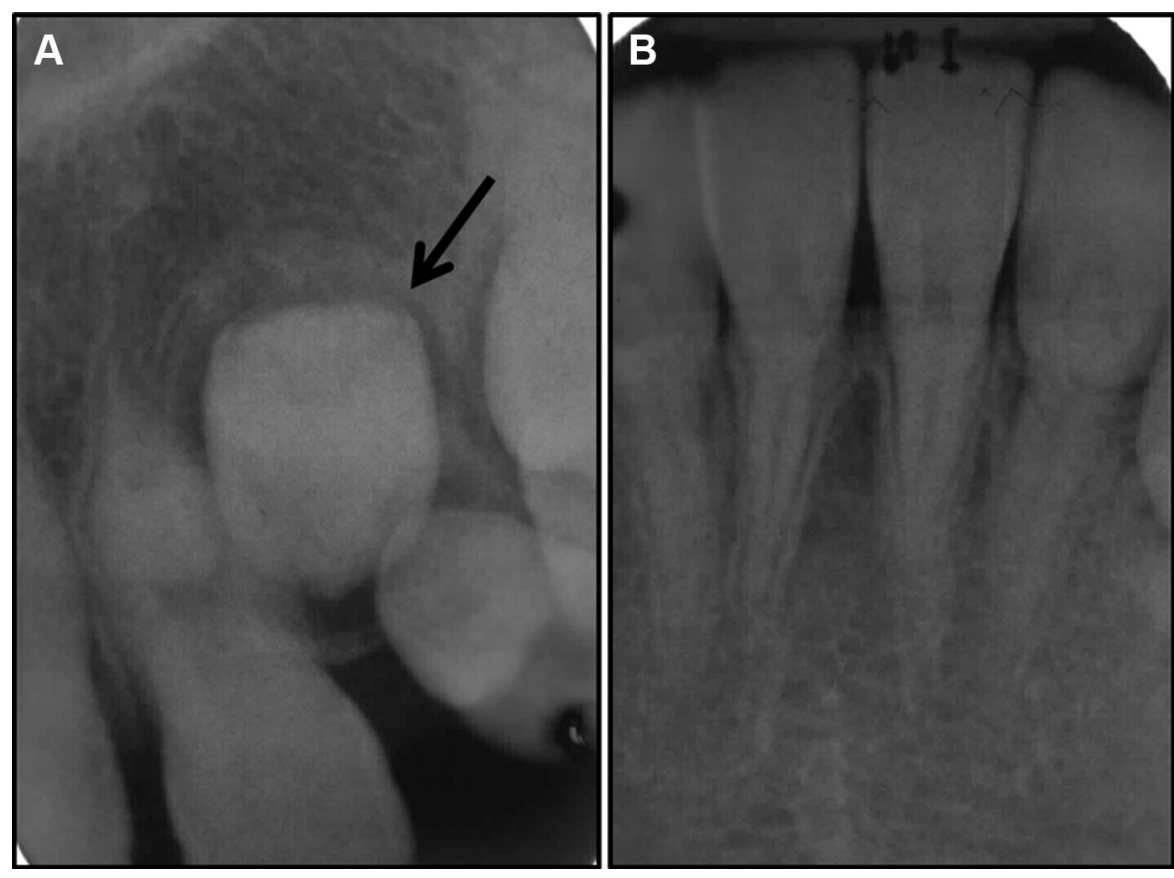

Fig. 3. The developing permanent canine (arrow) shows the pulp obliteration that is occurring and little root formation (A) (case 26). The lateral incisor has a marked pulp obliteration and shortened root. The same individual had shortened roots and evidence of pulpal calcifications in the mandibular incisors (B) (case 26).

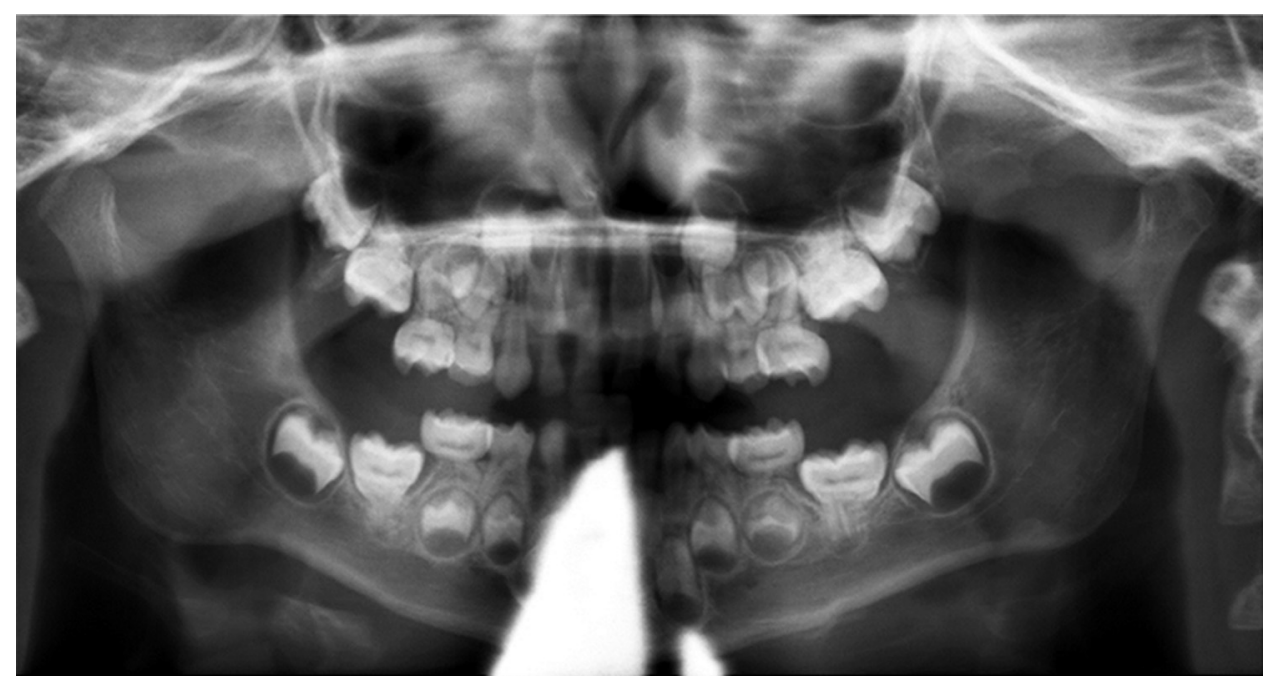

Fig. 4. The malformation was quite severe in some permanent molars and was associated with ectopic eruption as seen with the mandibular first permanent molars in this affected individual. The second primary molars also have short roots and an abnormal pulpal morphology (case 30).

\#244460), caused by mutations in the TBCE gene, which codes for a protein important in microtubule polymerization, is associated with abnormal root formation. $^{18}$ Interestingly, there are individuals and families with short roots that may only affect certain teeth. ${ }^{19}$ Taken together, these conditions, many of which are caused by genetic mutations that are now known, illustrate the tremendous diversity in genetic etiologies and in clinical phenotypes involving the dental root development.

Our knowledge of the genetic control of tooth root formation remains incomplete. ${ }^{20,21}$ Root morphology is thought to be determined by the Hertwig epithelial root sheath that proliferates from the enamel epithelium at the cementoenamel junction. In multirooted teeth, the root sheath invaginates at the area of root furcation. 


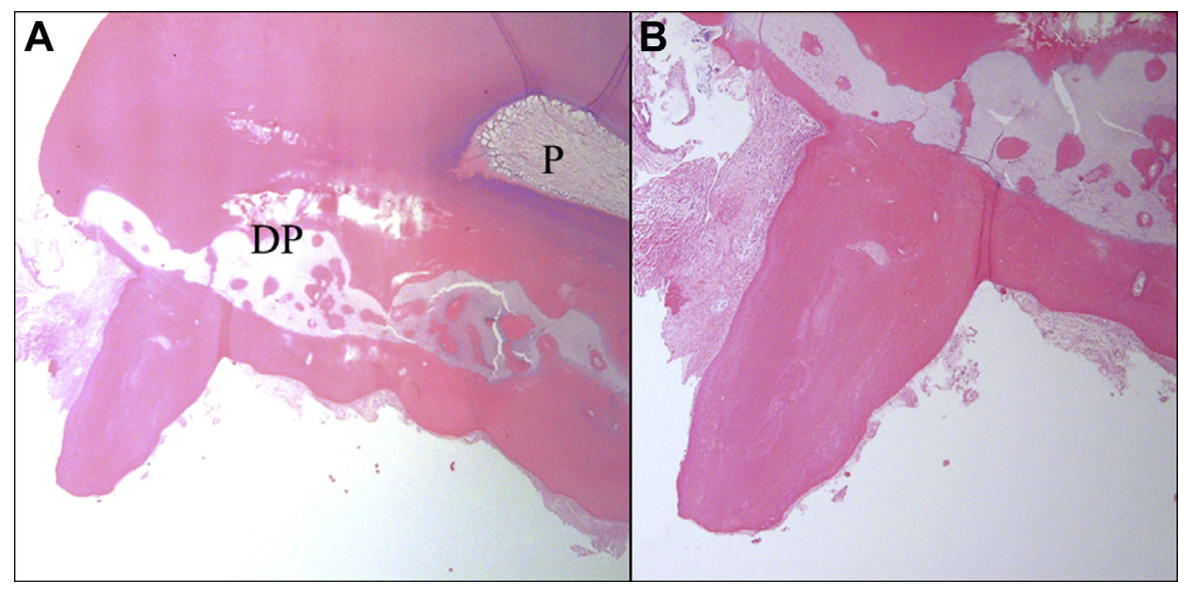

Fig. 5. Histologically the affected first permanent molars (A) (case 29) showed an area of pulpal tissue that originated in the coronal area of the crown but was terminated in its apical extent prematurely $(P)$ (original magnification $\times 20$ ). Cervical to this pupal area was a region of dysplastic dentin (DP) and fibrous tissue that was poorly organized and contained areas of mineralized tissue, which had the appearance of disorganized dentin. A small rootlike structure is seen projecting from this cervical area of the tooth $(\mathbf{B})$ in this higher magnification (original magnification $\times 40$ ) of Figure 5A.

Abnormal invagination of the root sheath can result in taurodontism, as occurs in the tricho-dento-osseous syndrome (OMIM \#190320), which is caused by mutations in the $D L X 3$ gene. ${ }^{22,23}$ The molecular controls regulating the transition from crown to root formation is not well understood, but evidence indicates that FGF10 is an important signaling molecule in this process. ${ }^{24}$ Regulation of the WNT proteins is critically important as illustrated by the abnormal gene expression and dental phenotype seen by disruption of Wntless (Wls), a chaperon protein involved in Wnt sorting and protein secretion. $^{25}$ Mutations in WNT10A are associated with hypodontia but also with changes in the root formation and taurodontism. ${ }^{26}$

Many different environmental stressors and conditions, such as regional odontodysplasia, are associated with the abnormal formation of the tooth roots. For example, trauma, infection, radiation, and certain chemotherapeutic agents for malignancies during early childhood can result in abnormal tooth and tooth root development. ${ }^{27,28}$ Severe infections, such as those occurring in Steven-Johnson syndrome or meningococcemia, can result in abnormal root formation. ${ }^{29}$ It seems likely that there are cases of abnormal root development that are caused by a genetic predisposition coupled with environmental triggers or stressors that result in altered cellular function and a clinical phenotype.

We have observed numerous cases of a localized and variable phenotype caused by abnormal tooth root development, affecting permanent first molars, sometimes permanent incisors, and primary second molars as well. A similar clinical phenotype was first reported by Witt et al., in 2014, in two individuals. ${ }^{1}$ One child was born healthy but at 9 months of age had severe osteomyelitis of the femur due to Staphylococcus aureus infection, which was treated with a combination of intravenously administered antibiotics. The second individual had a medical history, which was significant in that the mother had an astrocytoma and the affected individual was born prematurely. Histologic evaluation revealed dysplastic dentin formation in the area where the molar furcation would normally exist. ${ }^{30}$ Two additional reports have since been published, with many of the affected individuals (14 cases in total in the literature before the present report) having anomalies associated with neural development. ${ }^{2,30}$ Here, we report the characterization and related systemic conditions of this new developmental defect, which we now refer to as "molar rootincisor malformation", in an additional 30 cases. $^{2}$

\section{METHODS \\ Case selection}

The study protocol was reviewed and approved by the Institution Review Boards at the Seoul National University Dental Hospital and the University of North Carolina. Radiographs taken between February 2012 and May 2013 at the Seoul National University Dental Hospital were searched. Additional cases were identified through patients at the University of North Carolina School of Dentistry and cases referred for evaluation of this condition (2006-2014). In some cases, longitudinal follow-up was available. Generalized root malformation and cessation caused by anticancer therapy were excluded, and finally 30 cases were selected for this report. 


\section{Case analysis}

The extent of the patients' condition and their family history were recorded. Cases were reviewed for medical and dental histories by chart review and (telephone) interview, if necessary. Referral cases were followed up, when necessary, to assess medical and family histories.

\section{Morphologic and histologic analyses}

Teeth from three affected individuals were evaluated histologically. Teeth were decalcified, sectioned, and stained with hematoxylin and eosin and evaluated with light microscopy. One molar tooth was examined without decalcification and sectioned with a diamond saw, and the sections were examined with light microscopy.

\section{RESULTS}

There was no family history of similar dental anomalies reported in any of the cases; therefore, all cases were considered sporadic. Family members were not evaluated with radiography to determine if there were changes in the pulp or root status of the first permanent molars; however, cases of premature loss of the first permanent molar or abscess formation were not reported. Of the affected individuals, 18 were male, and 12 were female; the clinical phenotype and associated past medical history are presented in Table I. All cases showed involvement of the first permanent molars, with all four molars being affected, as illustrated in the female subject who reported meconium aspiration at birth but no other medical problems or significant illnesses in the neonatal period (Figure 1). Twelve cases had root malformations (Figure 2A) in the anterior permanent teeth, which varied in severity, with some cases having a marked constriction of the crown and an enamel furrow in the cervical third of the crown. Some anterior teeth had dens-in-dente and had developed periapical pathology in the absence of caries, trauma, or other discernable pulpal stressors (Figure 2B). The anterior teeth affected were usually maxillary central incisors, but permanent canines were also affected in four cases (Figure 3). It appears that the cases involving more teeth and mandibular incisors were more likely to be in people with more significant health challenges (e.g., cases \#4, \#5, \#9, $\# 13$, \#14, \#26, \#28), whereas only one case with incisor involvement was reported as healthy (case \#23). Primary second molars were also affected in 15 cases, and primary first molars were affected in one case (Figure 4).

Most of the patients reported health issues that had been detected or occurred during the neonatal period of life: seven patients reported meningomyelocele or sacral dimple, six reported meningitis, four reported preterm birth, and four reported chronic renal disease (see Table I). Other patients reported meconium aspiration, urinary tract infections, hemiplegia due to infantile stroke, cerebral thrombosis, possible cerebrovascular accident, and cerebral palsy with placenta previa. Four of the 30 affected individuals reported no major problems and were described as healthy. One of the four was born 5 weeks prematurely.

\section{Histologic evaluation}

The coronal dentin above the pulp chamber had a normal morphology with well-organized and wellarranged dentinal tubules that coursed from the dentinoenamel junction toward the pulp. The pulp chambers all had a greatly reduced dimension between the roof and floor of the pulp chamber (Figure 5) compared with normal teeth. There appeared to be a pulp chamber that started to form at the appropriate coronal location but then prematurely terminated, and then a highly irregular pulpal area was initiated cervical to this. The roof and floor of this dysplastic pulpal area tended to have an irregular outline, and there were also numerous pulpal inclusions that looked like disorganized dentin. This secondary dysplastic pulp area had frequent inclusions, which were not present in the more coronally positioned and more normalappearing pulp. In some cases, the molar pulpal areas showed inclusions of strongly eosinophilic material that looked similar to the enamel matrix. The root morphology was highly variable, and in one case, there was a small rootlike structure that formed on the distal side of the tooth, whereas a much more substantial root had formed on the mesial side (see Figure 4).

\section{DISCUSSION}

In this report, we provide further description of a newly identified developmental dental defect that affects primarily the tooth root but, in some cases, can also involve the cervical area of the clinical crown. The phenotype varies in severity and in the teeth affected. In the series reported here, the first permanent molars were always affected (100\%), with dysplastic root formation and a diminished pulp chamber making this the cardinal or primary feature of this unique developmental defect of the dentition. Secondary or less common defects included a similar root-pulp dysplasia of the second primary molars, which were affected in $50 \%$ of the cases. In the 16 cases previously reported, all involved the first permanent molars, similar to the results in the present study. Lee et al. (2014) reported a slightly higher involvement of maxillary central incisors-58\% compared with the $40 \%$ found in the present study. Affected permanent canines have not 
been described in previous reports of MRIM; and although less commonly affected in comparison with maxillary central incisors, they were involved in 13\% of the cases in the present report. One severe case in the present series also had the mandibular permanent incisors affected.

Previous reports of root malformation show that developmental defects can result from environmental stressors (e.g., anticancer therapy) occurring during critical developmental periods. ${ }^{31,32}$ The resulting phenotype of anticancer therapy or other environmental stressors, such as severe infections, is usually generalized involving essentially all developing teeth at the time of treatment. The clinical presentation of MRIM is markedly different from these environmentinduced root malformations in that the first permanent molar is always affected and the phenotype always includes dysplastic root formation and a diminished pulp chamber, which is restricted in its coronal-pulpal floor dimension. Agenesis of mandibular premolar root formation in hereditary renal disease has been reported, but the involvement pattern is different with cases in this study. ${ }^{33}$ Various hereditary conditions associated with abnormal root development may be generalized, as in Rothmund-Thomson syndrome (OMIM \#268400), or localized, as in short root anomaly (OMIM \#146400). In the case of MRIM, a contributing environmental stressor may have occurred around the time of completion of the crowns of the first permanent molars or incisors. Studies indicate that the maxillary central incisor crown is completely developed around age 4 years, whereas the first permanent molar crown is completed around age 3 years. ${ }^{34}$ Primary second molars complete their crown formation about 1 year of age. ${ }^{35}$

In this study, a variety of systemic conditions had occurred when the affected individuals were newborn or infants. Most of the MRIM cases in the present study and in previous reports show severe systemic conditions very early in life suggesting these root malformations are caused by a secondary effect of the systemic stressors. However, the disease pattern is not well correlated with the developmental timing of root development, given the marked time interval for the development of the cervical area of the different teeth affected, with the permanent molars not having root formation until early childhood and not in infancy. One might speculate that an environmental stressor affects certain cell lines (e.g., cervical loop stem cells) and that a sustained effect begins during crown formation but becomes increasingly devastating as the cells transition from crown to root formation. This might explain the histologic appearance of a double pulp chamber in molar crowns, as observed in the present and previous studies. ${ }^{1,30}$ A small number of individuals report not having any history of marked environmental stressor during the neonatal period or infancy and yet have the same clinical appearance as other MRIM-affected individuals. It is interesting that this developmental malformation has only recently been described and that MRIM certainly does not appear to affect the majority of individuals with the same types of environmental stressors or medical histories as those risk factors identified in the present and previous studies. An alternative explanation is that affected individuals have a unique genotype, with changes in one or more of the many genes that regulate dental formation, which predisposes them to this unique root malformation.

Meningomyelocele is the most common nonlethal congenital malformation in the spectrum of neural tube deficits and is a type of spina bifidas or spina bifida condition. ${ }^{36}$ This is caused by incomplete closure of vertebral column during embryogenesis. ${ }^{37}$ In this study, six cases had infantile meningitis, which is interestingly related to meningomyelocele in some cases. ${ }^{38}$ Evidence of a sacral dimple, which was observed in two cases in this study, can be a very mild phenotype of meningomyelocele, and urinary tract infection is frequently associated with meningomyelocele. ${ }^{39} \mathrm{~A}$ variety of genes, including the folate receptor and folate carrier genes, may be associated with meningomyelocele. Evaluation of tooth agenesis in people with meningomyelocele did not indicate an increased prevalence of missing teeth, and the patients did not mention any dental malformation or root anomalies. ${ }^{40}$ Furthermore, renal damage, which is a frequent finding, occurs in up to $40 \%$ of individuals with spina bifida. ${ }^{41}$ One cannot lump all of the systemic conditions in the present study into a common category; however, the most prevalent stressor or associated malformation appears to be neurologic in nature.

Molecular control of root formation is known to involve a number of pathways and evidence indicates that Hedgehog and FGF are both important in the regulation of the Hertwig epithelial root sheath. ${ }^{21}$ Differential expression of factors, such as follistatin and Fgf10, have been shown to change when crown morphogenesis shifts to root formation. ${ }^{24}$ Determining if individuals with polymorphisms in a critical gene or constellation of genes that are important in root formation are predisposed to developing MRIM will help advance our understanding of the pathogenesis of MRIM. Evaluating the potential environmental stressors that may be at play also will advance our knowledge of MRIM as additional cases of this newly described developmental defect of teeth are identified.

\section{CONCLUSIONS}

This report makes a significant addition to the number of cases described to date and shows there is a diverse 
range of severity related to the teeth affected and the extent of the malformation (e.g., root/crown malformation). Clinicians identifying cases of MRIM should carefully evaluate them for an increased risk for ectopic eruption and permanent incisor malformations that can lead to pulpal necrosis.

\section{REFERENCES}

1. Witt CV, Hirt T, Rutz G, Luder HU. Root malformation associated with a cervical mineralized diaphragm - a distinct form of tooth abnormality? Oral Surg Oral Med Oral Pathol Oral Radiol. 2014;117:e311-e319.

2. Lee HS, Kim SH, Kim SO, et al. A new type of dental anomaly: molar-incisor malformation (MIM). Oral Surg Oral Med Oral Pathol Oral Radiol. 2014;118:101-109:e103.

3. Jernvall J, Thesleff I. Tooth shape formation and tooth renewal: evolving with the same signals. Development. 2012;139:34873497.

4. Hu S, Parker J, Wright JT. Towards unraveling the human tooth transcriptome: the dentome. PLoS One. 2015;10:e124801.

5. Thesleff I. The genetic basis of tooth development and dental defects. Am J Med Genet A. 2006;140:2530-2535.

6. Suckling G, Pearce E. Developmental defects of enamel in a group of New Zealand children: their prevalence and some associated etiological factors. Community Dent Oral Epidemiol. $1984 ; 12: 177-184$.

7. Wright JT, Carrion IA, Morris C. The molecular basis of hereditary enamel defects in humans. J Dent Res. 2015;94:52-61.

8. Witkop CJ Jr. Amelogenesis imperfecta, dentinogenesis imperfecta and dentin dysplasia revisited: problems in classification. J Oral Pathol. 1988:17:547-553.

9. McKnight DA, Simmer JP, Hart PS, Hart TC, Fisher LW. Overlapping DSPP mutations cause dentin dysplasia and dentinogenesis imperfecta. J Dent Res. 2008;87:1108-1111.

10. Kim JW, Simmer JP. Hereditary dentin defects. J Dent Res. 2007;86:392-399.

11. Bloch-Zupan A, Jamet X, Etard C, et al. Homozygosity mapping and candidate prioritization identify mutations, missed by wholeexome sequencing, in SMOC2, causing major dental developmental defects. Am J Hum Genet. 2011;89:773-781.

12. Cherkaoui Jaouad I, El Alloussi M, Laarabi FZ, Bouhouche A, Ameziane R, Sefiani A. Inhabitual autosomal recessive form of dentin dysplasia type I in a large consanguineous Moroccan family. Eur J Med Genet. 2013;56:442-444.

13. Rutsch F, MacDougall M, Lu C, et al. A specific IFIH1 gain-offunction mutation causes Singleton-Merten syndrome. Am J Hum Genet. 2015:96:275-282.

14. Lyles KW, Burkes EJ, Ellis GJ, Lucas KJ, Dolan EA, Drezner MK. Genetic transmission of tumoral calcinosis: Autosomal dominant with variable clinical expressivity. J Clin Endocrinol Metab. 1985;60:1093-1096.

15. Foster BL, Ramnitz MS, Gafni RI, et al. Rare bone diseases and their dental, oral, and craniofacial manifestations. J Dent Res. 2014;93:7S-19S.

16. Gripp KW, Johnson C, Scott CI Jr, et al. Expanding the phenotype of SPONASTRIME dysplasia to include short dental roots, hypogammaglobulinemia, and cataracts. Am J Med Genet A. 2008;146A:468-473.

17. Majumdar U, Arya G, Singh S, et al. Oro-dental findings in Bardet-Biedl syndrome. BMJ Case Rep. 2012;2012:pii: bcr1220115320.
18. Moussaid Y, Griffiths D, Richard B, et al. Oral manifestations of patients with Kenny-Caffey Syndrome. Eur J Med Genet. 2012;55:441-445.

19. Puranik CP, Hill A, Henderson Jeffries K, Harrell SN, Taylor RW, Frazier-Bowers SA. Characterization of short root anomaly in a Mexican cohort-hereditary idiopathic root malformation. Orthod Craniofac Res. 2015;18:62-70.

20. Wright JT. The molecular etiologies and associated phenotypes of amelogenesis imperfecta. Am J Med Genet A. 2006;140: $2547-2555$

21. Huang XF, Chai Y. Molecular regulatory mechanism of tooth root development. Int J Oral Sci. 2012;4:177-181.

22. Wright JT, Kula K, Hall K, Simmons JH, Hart TC. Analysis of the tricho-dento-osseous syndrome genotype and phenotype. Am J Med Genet. 1997;72:197-204.

23. Price JA, Bowden DW, Wright JT, Pettenati MJ, Hart TC. Identification of a mutation in DLX3 associated with tricho-dentoosseous (TDO) syndrome. Hum Mol Genet. 1998;7:563-569.

24. Yokohama-Tamaki T, Ohshima H, Fujiwara N, et al. Cessation of Fgf10 signaling, resulting in a defective dental epithelial stem cell compartment, leads to the transition from crown to root formation. Development. 2006;133:1359-1366.

25. Bae CH, Kim TH, Ko SO, Lee JC, Yang X, Cho ES. Wntless regulates dentin apposition and root elongation in the mandibular molar. J Dent Res. 2015;94:439-445.

26. Yang J, Wang SK, Choi M, et al. Taurodontism, variations in tooth number, and misshapened crowns in Wnt10 a null mice and human kindreds. Mol Genet Genomic Med. 2015;3:40-58.

27. Marec-Berard P, Azzi D, Chaux-Bodard AG, Lagrange $H$, Gourmet R, Bergeron C. Long-term effects of chemotherapy on dental status in children treated for nephroblastoma. Pediatr Hematol Oncol. 2005;22:581-588.

28. Tewari N, Pandey RK. Root hypoplasia: an unusual sequela to primary tooth trauma. Dent Traumatol. 2010;26:115-117.

29. Bajaj N, Madan N, Rathnam A. Cessation in root development: ramifications of "Stevens-Johnson" syndrome. J Indian Soc Pedod Prev Dent. 2012:30:267-270.

30. Lee HS, Kim SH, Kim SO, et al. Microscopic analysis of molarincisor malformation. Oral Surg Oral Med Oral Pathol Oral Radiol. 2015:119:544-552.

31. Holtta P, Alaluusua S, Saarinen-Pihkala UM, Wolf J, Nyström M, Hovi L. Long-term adverse effects on dentition in children with poor-risk neuroblastoma treated with high-dose chemotherapy and autologous stem cell transplantation with or without total body irradiation. Bone Marrow Transplant. 2002;29:121-127.

32. Cubukcu CE, Sevinir B, Ercan I. Disturbed dental development of permanent teeth in children with solid tumors and lymphomas. Pediatr Blood Cancer. 2012;58:80-84.

33. Brin I, Zilberman Y, Galili D, Fuks A. Eruption of rootless teeth in congenital renal disease. Oral Surg Oral Med Oral Pathol. 1985:60:61-64.

34. Liversidge HM. Crown formation times of human permanent anterior teeth. Arch Oral Biol. 2000;45:713-721.

35. Lunt RC, Law DB. A review of the chronology of calcification of deciduous teeth. J Am Dent Assoc. 1974;89:599-606.

36. Tulipan N, Sutton LN, Bruner JP, Cohen BM, Johnson M, Adzick NS. The effect of intrauterine myelomeningocele repair on the incidence of shunt-dependent hydrocephalus. Pediatr Neurosurg. 2003:38:27-33.

37. Haq IZ, Akmal S, Chandler CL, Bassi S. Review of practices in myelomeningocoele repair at King's College Hospital, London. Br J Neurosurg. 2012;26:851-855.

38. Fiumara F, Foti N, Gambardella A, et al. Purulent meningitis due to spontaneous anterior sacral meningocele perforation. Case report. Ital J Neurol Sci. 1989;10:211-213. 
39. Madden-Fuentes RJ, McNamara ER, Lloyd JC, et al. Variation in definitions of urinary tract infections in spina bifida patients: A systematic review. Pediatrics. 2013;132:132-139.

40. Linderstrom A, Samuelsson L, Huggare J. Is tooth agenesis related to brainstem anomalies in myelomeningocele patients with Chiari II malformations? Acta Odontol Scand. 2002;60: 337-340.

41. Muller T, Arbeiter K, Aufricht C. Renal function in meningomyelocele: risk factors, chronic renal failure, renal replacement therapy and transplantation. Curr Opin Urol. 2002;12:479-484.
Reprint requests:

Jung-Wook Kim, DDS, PhD

Department of Molecular Genetics

Department of Pediatric Dentistry \& Dental Research Institute

School of Dentistry

Seoul National University

275-1 Yongon-dong

Chongno-gu

Seoul 110-768, Korea

pedoman@snu.ac.kr 